Fourth International Conference on Sustainable Construction Materials and Technologies http://www.claisse.info/Proceedings.htm

SCMT4

Las Vegas, USA, August 7-11, 2016

\title{
Progressing towards a Green and Low Carbon Cement Industry - China's Experience
}

\author{
SuiTongbo ${ }^{1 \mathrm{a}}$, and Cai Yuliang ${ }^{1 \mathrm{~b}}$ \\ ${ }^{1}$ Sinoma Research Institute, Sinoma International Engineering Co.Ltd. Beijing 100102, China. \\ ${ }^{1 a}$ Email: <suitongbo@sinoma.com.cn>, ${ }^{1 b}$ Email: <caiyuliang@126.com>.
}

\begin{abstract}
China's recent progress in cement sector on energy saving and emission mitigation is introduced focusing on two typical innovative technological solutions as best available technologies to further saving the natural resources and reducing the $\mathrm{CO}_{2}$ emission for cement making and enhancing the performance of cement and concrete. The first one is co-processing of municipal solid wastes (MSW) with cement kilns, which has been proved as a reliable and sound management of urban wastes. A demonstration co-processing project with a capacity of pretreatment $450 \mathrm{t} / \mathrm{d}$ of municipal solid wastes in line with a cement kiln with a capacity of $5000 \mathrm{t} / \mathrm{d}$ clinker is included. The second solution is the development of belite based and belite-sulfoaluminate based low energy and low carbon clinker cements. Better performances of the resultant cements and concrete have been demonstrated through their application in real construction projects.Future perspective of cement industry is also given showcasing a roadmap towards a green and low carbon cement Industry.
\end{abstract}

\section{INTRODUCTION}

Cement production by far has been considered as one of the largest industrial $\mathrm{CO}_{2}$ emission sources. As sustainability has become the global trend in the 21 st century, cement, as the main binders making the second world largest commodity after water, faces great challenge. This issue is of great significance specifically for China due to China's huge volume of cement production (2.48 billion metric tons in 2014 in China) accounting for about $60 \%$ of the world cement production.

Great effort has been made in cement sector in China since 2006 in terms of government policy enforcement on industrial re-structuring, energy consumption and emission reduction, especially De-SOx and De-NOx, technical innovation on new binders development and achieving high efficient and environmental friendly cement production. One important feature of Chinese cement industry is the 
continuously enhanced use of clinker substitutes, i.e., blending materials which leads to a steady decrease of clinker factor from 0.73 in 2005 to 0.57 in 2014 for Chinese cement. The second feature is the installation of waste heat recovery process for co-generation in $70 \%$ of modern rotary kiln facilities to reduce the power consumption and thus the emission of $\mathrm{CO}_{2}$ and SOx, NOx, etc. Specifically this paper presents two typical innovative technological solutions as best available technologies (BAT) in China.

The first one is to recycle MSW through co-processing technology with cement kilns. This is also one of the countermeasures to deal with the increasingly big challenge of fast urbanization process of China which produces annually 1650 million tons of urban wastes [Chen L., et al, 2010]. It has been found through investigation in 2013 that the wide spread of over 1800 modern cement kilns in each province of China matches well with the population distribution density [Yang X., et al, 2003]. Investigation also indicated an average daily garbage generation in China about $1.0 \mathrm{~kg} / \mathrm{capita}$.

The second one is to enhance the performance of cement and concrete through developing and using belite based low carbon clinker cements. Progress in China on development and application of cements containing belite and/or sulfoaluminate, i.e., reactive belite-rich Portland cements (RBPC) and belite-calcium sulfoaluminate cement (BCSA) as examples is introduced in view to the revival and intensive research on belite cements [Chatterjee, A. K., 1996, Sui T., et al, 1999, 2003, 2004] and BCSA for decades worldwide [Mehta, P. K., 1980, Glasser, F. P., Zhang, L., 2001, Gartner E., et al, 2007].

\section{BAT 1: Co-Processing of MSW with Cement Kilns}

MSW in China is mostly unsorted with complex compositions, high moisture content and low calorific value. They also contain interference elements $\left(\mathrm{K}^{+}, \mathrm{Na}^{+}, \mathrm{SO}_{3}{ }^{=}, \mathrm{Cl}^{-}\right.$, and $\mathrm{P}_{2} \mathrm{O}_{5}$, etc. $)$ that might impose adverse effects on the cement production, environment and clinker quality.

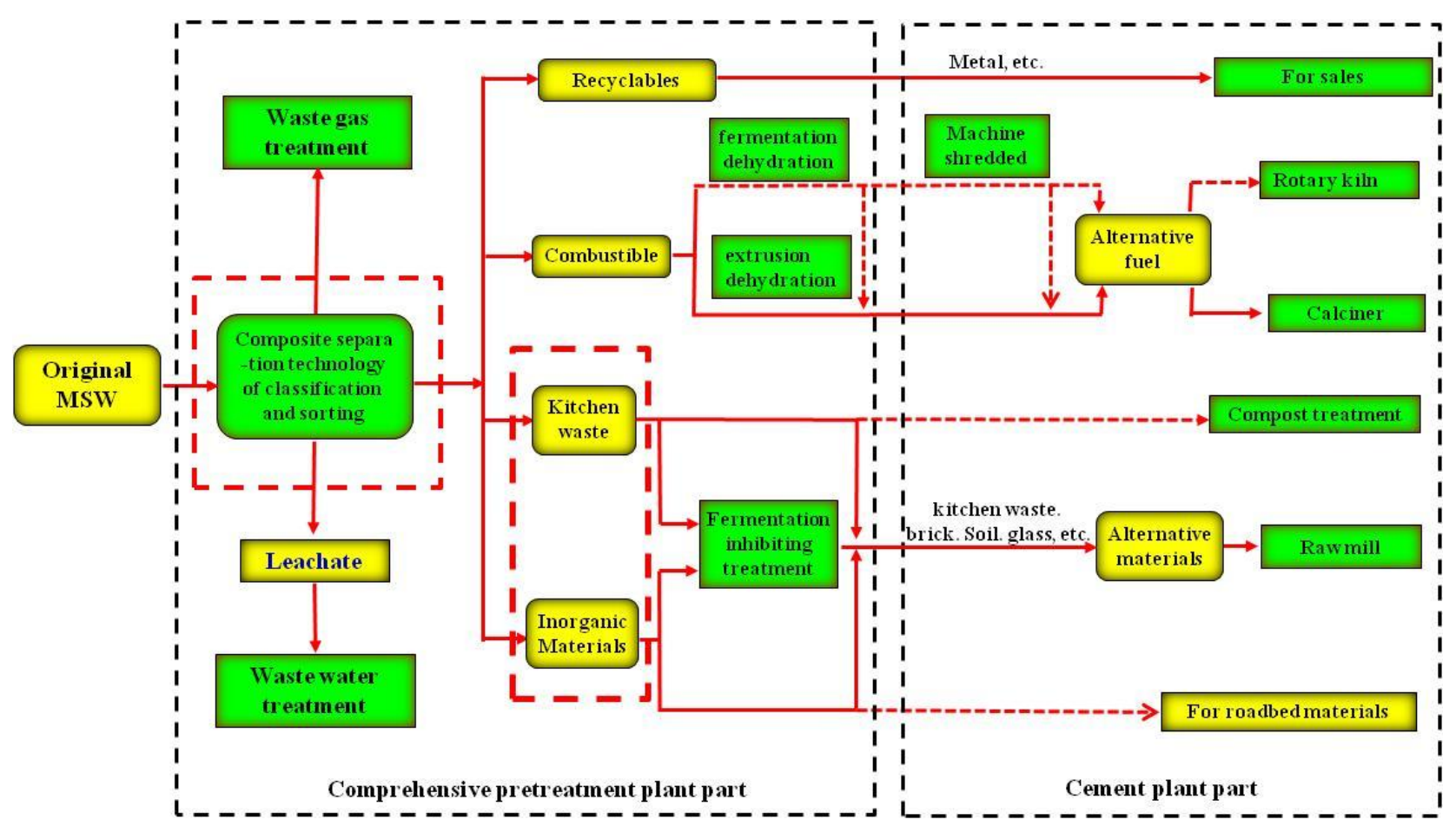

Figure 1. Sinoma Co-Processing MSW Flow Chart 
Process Briefing. Figure 1 is the MSW co-processing flow chart consisting of the pretreatment system and cement production receiving system based on the demonstration project in Liyang, Jiangsu province, China pretreating $450 \mathrm{t} / \mathrm{d}$ of MSW and co-processing with 5000t clinker capacity kiln per day.

The original MSW collected by municipal sanitation system is sent to the comprehensive pretreatment plant and separated into four different categories of substances as leachate (natural and after squeezed), metal wastes, combustible materials (CM) on the sieve, incombustible materials (ICM) under the sieve.

Effect of Moisture Content in ICM \& CM on Capacity of Kiln for Co-Processing. Relationship between moisture content and the maximum acceptance of ICM in different capacity of cement kilns is shown in Figure 2 through thermodynamic modeling analysis. It can be seen that $5000 \mathrm{t} / \mathrm{d}$ cement plant can dispose 450t/d-650t/d MSW when its moisture content is 50\%-70\%, 850t/d MSW when its moisture content is decreased to $40 \%$, which gives a more flexible choices for process design.

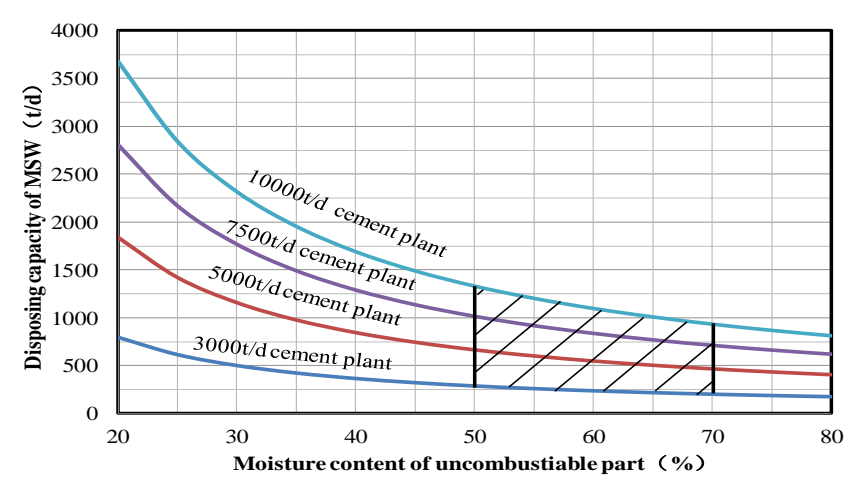

Figure 2. The Relationship between Moisture Content and the Maximum Acceptance of ICM part in Different Capacity of Cement Kilns

Moisture content also influences the addition of CM into the calciner. Relation between moisture of CM and the heat contribution for calciner of different calorific value of $\mathrm{CM}$ (dry basis) is modeled on the basis of 5000t/d clinker kiln disposing 150tons of CM. The result of the thermal contribution of burning CM in calciner to the system is indicated in Figure 3.

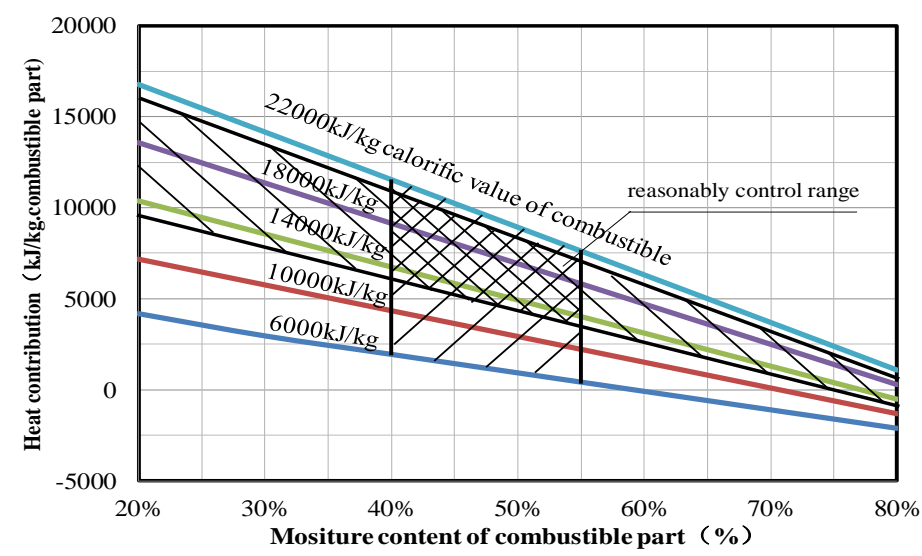

Figure 3. Relation between the Moisture of CM Part and the Heat Contribution for Calciner of Different Calorific value of CM (Dry Basis) 
When the calorific value of CM (dry basis) is $6000 \mathrm{~kJ} / \mathrm{kg}$, moisture of CM has to be controlled less than $60 \%$ in order to ensure positive heat contribution, or when the calorific value of $\mathrm{CM}(\mathrm{dry}$ basis $)$ is $10000 \mathrm{~kJ} / \mathrm{kg}$, the moisture of CM less than $70 \%$ can give a positive heat contribution. Therefore, the moisture of CM must be controlled technically strict and economically reasonable. The suggestion is to control the moisture content ranging at $40 \%-60 \%$ though the lower the better.

Interference Elements in MSW and the Dosage of MSW for Co-Processing. Chlorine $(\mathrm{Cl})$ among all the interference elements imposes the largest impact on co-processing MSW with modern kiln. The $\mathrm{Cl}$ content of MSW is 0.3\%-0.5\% [Yang X., et al, 2003], which is much higher than normal raw material for cement making. Chinese standards also specify the limit of $\mathrm{Cl}$ less than $0.06 \%$ in PC. As a result the limit of $\mathrm{Cl}$ content in raw meal is normally recommended as $0.02 \%$. Within this context, effect of $\mathrm{Cl}$ content on the addition of calcined MSW in kiln feed is shown as Figure 4.

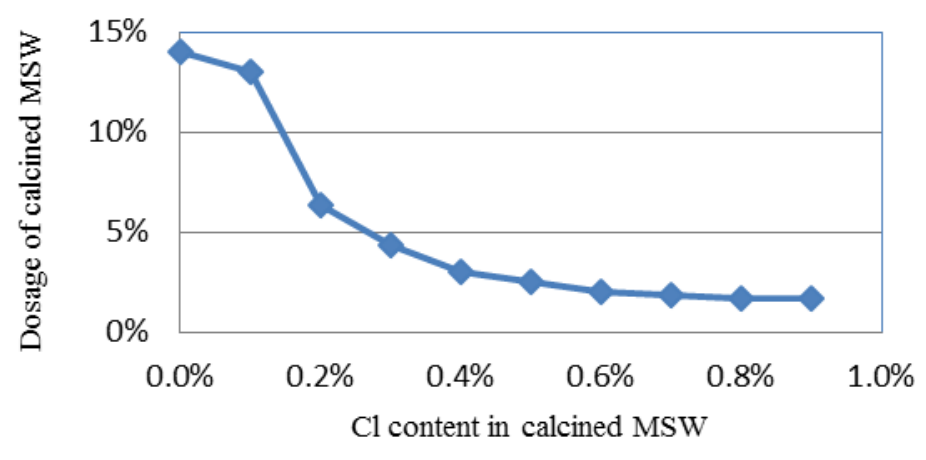

Figure 4. Dosage of Calcined MSW as a Function of its Cl Content

Limitation on interference elements in kiln feed is thus given as $\mathrm{Cl}$ less than $0.015 \%, \mathrm{SO}_{3} / \mathrm{R}_{2} \mathrm{O} 0.6-1.0$ and $\mathrm{R}_{2} \mathrm{O}$ less than 1.0 based on laboratory and field results without bypass system. Further study also reveals that it is unnecessary to install bypass system when using 5000t/d clinker kiln to deal with $150 \mathrm{t} / \mathrm{d}$ of MSW. Yet bypass is needed when dealing with 500t/d of MSW if $\mathrm{Cl}$ content in MSW exceeds $0.2 \%$.

Outcome of Co-Processing Demonstration Project. With the continuous operation of the project in co-processing 450t/d of MSW in line with 5000t/d clinker kiln, outstanding social, environmental and proper economic benefits have been achieved on a year basis:

- Clinker quality and output: same as without co-processing;

- Dioxin emission: 0.0593ng-TEQ/ $/ \mathrm{Nm}^{3}$;

- $\quad$ NOx and TOC emission: $40 \%$ reduced than without co-processing;

- Minor elements: same as without co-processing;

- Power saving: 6,046,000 kWh, equivalent $\mathrm{CO}_{2}$ emissions reduction: 6027.9 tons;

- $\quad \mathrm{NOx}$ and $\mathrm{SO}_{2}$ emission reduced: 90.7 tons and 181.4tons;

- Standard coal saving: 16,000 tons, equivalent to reduction of $\mathrm{CO}_{2}$ emissions of 38,720 tons and NOx emissions of 738.7 tons; 
- Indirect saving: 3.3acres of fill land

\section{BAT 2: LOW CARBON CLINKER CEMENTS \& RESULTANT CONCRETES}

Reactive belite-rich Portland cement $\left(\mathrm{C}_{2} \mathrm{~S}-\mathrm{C}_{3} \mathrm{~S}-\mathrm{C}_{3} \mathrm{~A}-\mathrm{C}_{4} \mathrm{AF}, \mathrm{RBPC}\right)$ has been developed in China since 1996. The industrial production of the RBPC proved that up to 10-20\% of energy-saving can be achieved and thus leads to a reduction in $\mathrm{CO}_{2}$ emission about $10 \%$ [SUI T., et al, 1998]. The performance and field application of RBPC are briefed below. Latest progress on newly developed RBPC and belite based calcium sulfoaluminate cement $\left(\mathrm{C}_{2} \mathrm{~S}-\mathrm{C}_{4} \mathrm{~A}_{3} \overline{\mathrm{S}}-\mathrm{C}_{4} \mathrm{AF}, \mathrm{BCSA}\right)$ is also introduced

Performance and Application of RBPC. Performance of belite-rich Portland cement (RBPC) was evaluated in comparison with alite based normal Portland cement (PC). All the tests unless specified were conducted on the basis of Chinese standards GB 175 unless specified. Mortar strength test were conducted with the sand/cement ratio is 2.5 and w/c ratio is 0.44 . The basic characteristics of the cements are shown in Table 1.

Table 1. Typical Data on the Properties of Cements, Fresh Pastes and Mortars

\begin{tabular}{|c|c|c|c|c|c|c|c|}
\hline \multirow[t]{2}{*}{ No } & \multicolumn{2}{|c|}{ Main minerals } & \multirow{2}{*}{$\begin{array}{l}\mathrm{SSA} \\
\mathrm{m}^{2} / \mathrm{kg}\end{array}$} & \multirow{2}{*}{$\begin{array}{c}\text { Water demand } \\
\%\end{array}$} & \multicolumn{2}{|c|}{ Setting (hr:min) } & \multirow{2}{*}{$\begin{array}{c}\text { Mortar flow } \\
\mathrm{mm}\end{array}$} \\
\hline & $\mathrm{C}_{3} \mathrm{~S}$ & $\mathrm{C}_{2} \mathrm{~S}$ & & & Initial & Final & \\
\hline $\mathrm{RBPC}$ & 24.69 & 52.96 & 364 & 22.4 & $2: 35$ & $3: 45$ & 137 \\
\hline $\mathrm{PC}$ & 52.36 & 24.49 & 367 & 27.4 & $2: 05$ & 3:05 & 131 \\
\hline
\end{tabular}

Strength under standard curing temperature $\left(20^{\circ} \mathrm{C}\right)$. Compressive strength development of RBPC and $\mathrm{PC}$ under $20^{\circ} \mathrm{C}$ is shown in Figure 5.

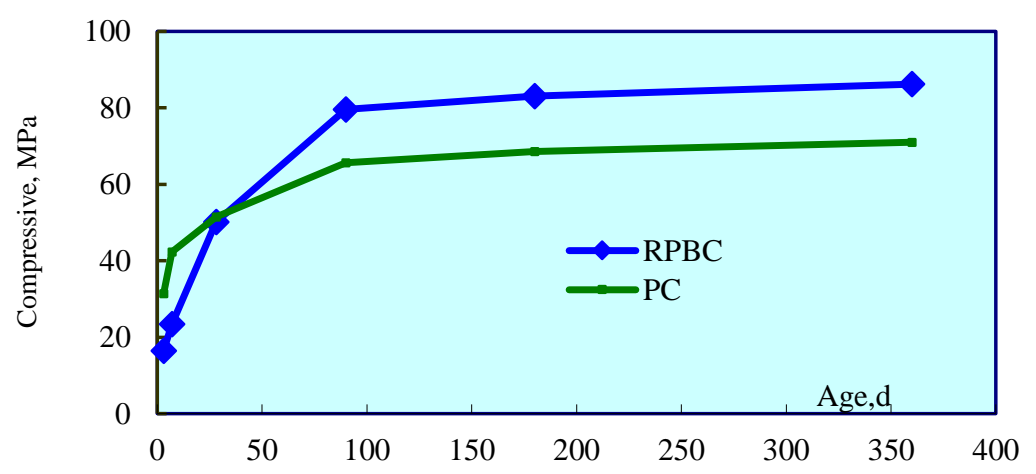

Figure 5: Strength Development of RBPC and PC

Though the early age strength of RBPC (3-day and 7-day) is lower than that of PC, both achieve equivalent 28-day strength. The long term strength of RBPC at 3 to 12-month ages goes over $10 \mathrm{MPa}$ higher than those of PC. Similar results have been found for high strength high performance concrete (HPC) with strength grade C60 and C80 prepared by RBPC and PC. 
Strength under elevated curing temperature. Figure 6 is the comparison of RBPC and PC strength development under curing of $20^{\circ} \mathrm{C}, 38^{\circ} \mathrm{C}, 52^{\circ} \mathrm{C}$ and $70^{\circ} \mathrm{C}$. RBPC- 15 and PC-20 represent RBPC and PC inter-blended with $15 \%$ of slag and $20 \%$ of fly ash respectively. The molding and curing tests were conducted in accordance with API Spec.10A.

It is shown that at 1-day age both the strengths of RBPC series and PC series increase with the increase of curing temperatures, while RBPC series have higher rate of strength increase. What is worth mentioning is that it is possible to make 1-day strength of RBPC equivalent to the level of PC.

The most different aspect for RBPC and PC comes up later in 28-day strength development. The increase of curing temperature results in a continuous increase of the strength for RBPC series, while PC series give exactly the opposite result. One main reason for the difference between alite based and belite based cements is that the excessively fast hydration of alite under higher curing temperature encapsulates the mineral particles and thus hinders the further hydration at following age [Taylor, H.F.W., 1997].
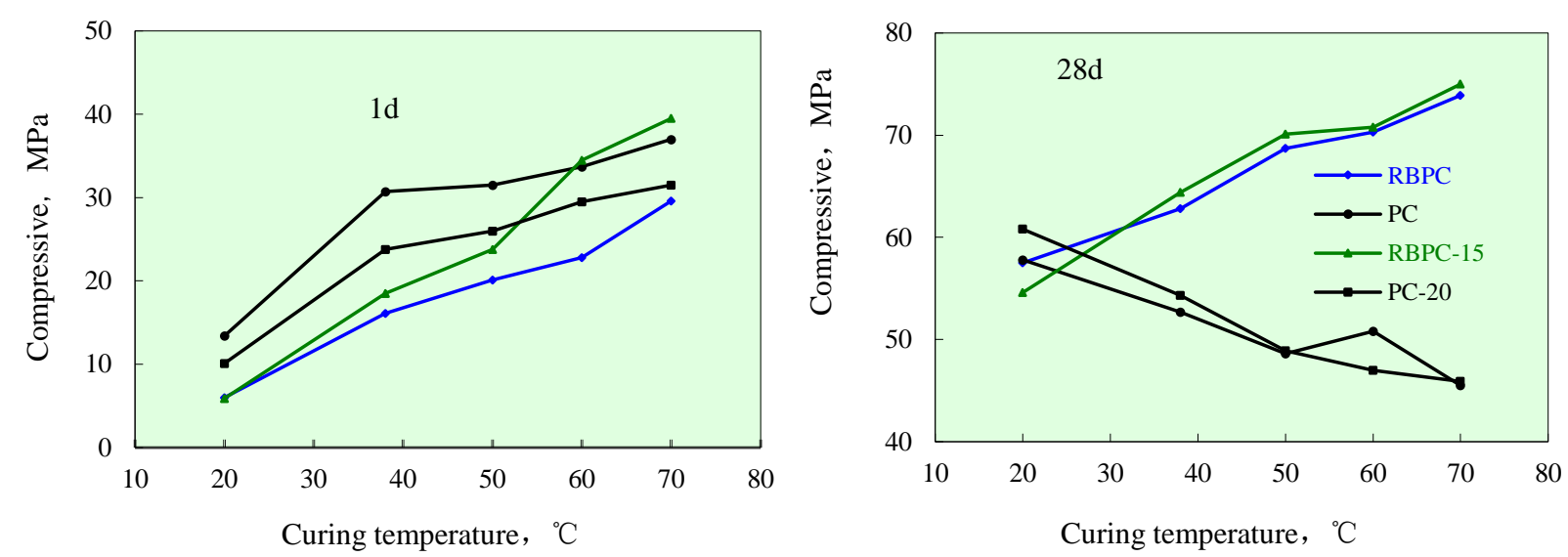

Figure 6. Comparison of RBPC and PC under varying curing temperatures

Heat Evolution Characteristics. It is known that excess heat accumulation may be detrimental to concrete due to the possible occurring of thermal stress and cracking. It is thus crucial for concrete, especially mass concrete, to control the temperature rise. Figure 7 is the hydration heat liberation of PC and RBPC. The hydration heat evolved for RBPC at corresponding age decreases by more than $20 \%$ compared with those for PC up to 1 year.

Evaluation for field concrete is in good agreement with the above-mentioned results. The adiabatic temperature rise of RBPC massive concrete (RBPCC) is $3-5^{\circ} \mathrm{C}$ lower that of moderate heat cement concrete (MHCC) mainly used for Three Gorges dam, and the time of the appearance of peak temperature for RBPC is also delayed [Sui T., et al, 2006]. On-line monitoring of temperature rise of internal concretes of RBPCC and MHCC at the right bank of Three Gorges dam shown in Figure 8 also confirmed the result. 


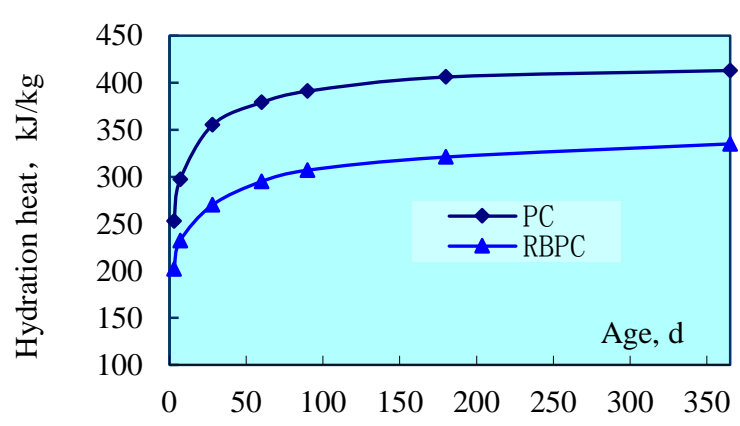

Figure 7. Hydration Heat of PC \& RBPC

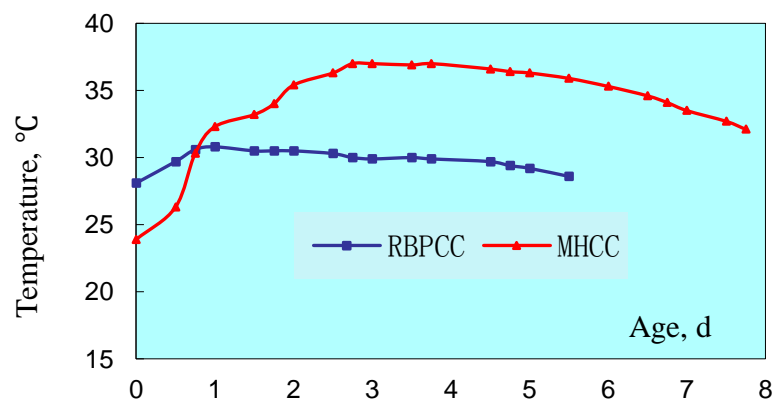

Figure 8. On-site Monitoring of Maximum Temperature rise of RBPCC and MHCC

Better chemical corrosion resistance and $40 \%-50 \%$ less of drying shrinkage were found for RBPC compared with PC.

Application of RBPC in Practical Concrete Structures. The advantage of RBPC in lower hydration heat liberation and higher later age strength development enable the use of RBPC first of all to make massive concrete as well as high strength HPC which is in progressing at present.

The first and most important use of RBPC in China is for the $3^{\text {rd }}$ phase of Three Gorges Project. RBPCC exhibits better cracking resistance than MHCC in terms of $5^{\circ} \mathrm{C}$ lower of temperature rise. This is not only beneficial to the cracking resistance to the thermal stress of massive concrete, but to a big potential saving of direct investment for cooling the fresh concrete to $7^{\circ} \mathrm{C}$ as well.

Latest Progress on Newly Developed RBPC and BCSA. Continuous effort has been made on developing low carbon clinker cements. The following are some of the results on newly developed RBPC (NRBPC) and belite based calcium sulfoaluminate cement BCSA.

Table 2 shows the basic characteristics of the two new low carbon clinker cements as compared with RBPC and normal PC.

Table 2. Typical characteristics of cement properties

\begin{tabular}{|c|c|c|c|c|c|}
\hline \multirow{2}{*}{ No } & \multicolumn{3}{|c|}{ Main clinker minerals } & \multirow{2}{*}{$\begin{array}{c}\text { SSA } \\
\mathrm{m}^{2} / \mathrm{kg}\end{array}$} & $\begin{array}{c}\text { Mortar flow } \\
\mathrm{mm}\end{array}$ \\
\cline { 2 - 3 } & $\mathrm{C}_{3} \mathrm{~S}$ & $\mathrm{C}_{2} \mathrm{~S}$ & $\mathrm{CSA}$ & 397 & 196 \\
\hline NRBPC & 26.40 & 46.17 & 3.46 & 344 & 220 \\
\hline RBPC & 24.69 & 52.96 & 0 & 351 & - \\
\hline BCSA & 0 & 48.35 & 36.89 & 367 & 199 \\
\hline PC & 52.36 & 24.49 & 0 & & \\
\hline
\end{tabular}

Mortar Strength Development. The mortar compressive strength test results of the three types of cements under present Chinese standard (water/cement $=0.5$, cement/sand=1:3) is shown in Figure 9. It can be seen that though the 3-day strength of NRBPC is similar to RBPC and lower than PC, it increases rapidly between 3 to 7 days and has the equivalent 7-day strength with PC. The long term strength of NRBPC 
goes more than 30MPa higher than PC at 28-day and 20MPa higher than RBPC at 3-month.

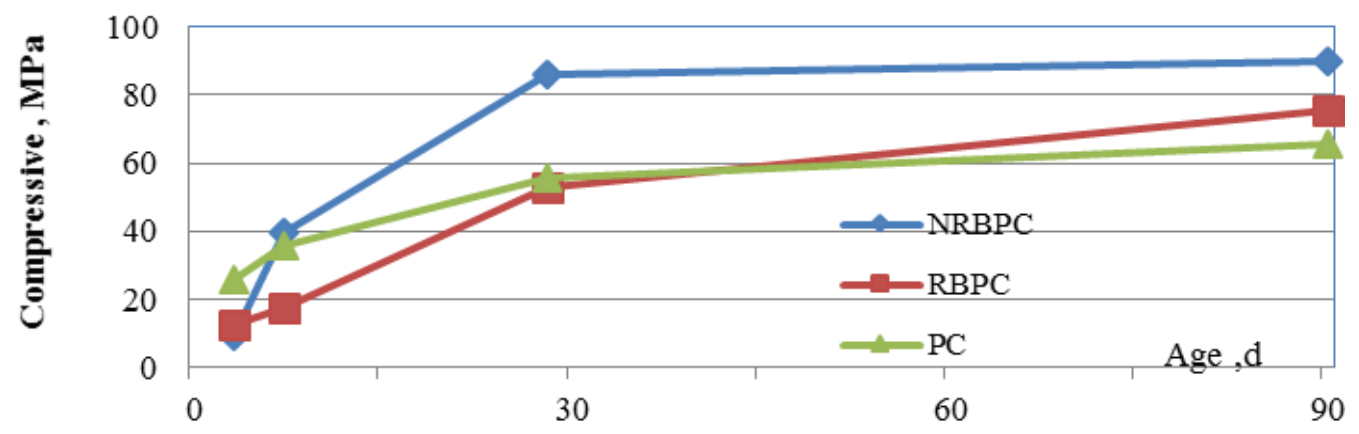

Figure 9. Strength development of Three Cements

Heat Evolution Characteristics. The hydration process of NRBPC, RBPC and PC with the $0.5 \mathrm{w} / \mathrm{c}$ ratio and $20^{\circ} \mathrm{C}$ were studied by using an isothermal conductive calorimeter, as shown in Figure 10.

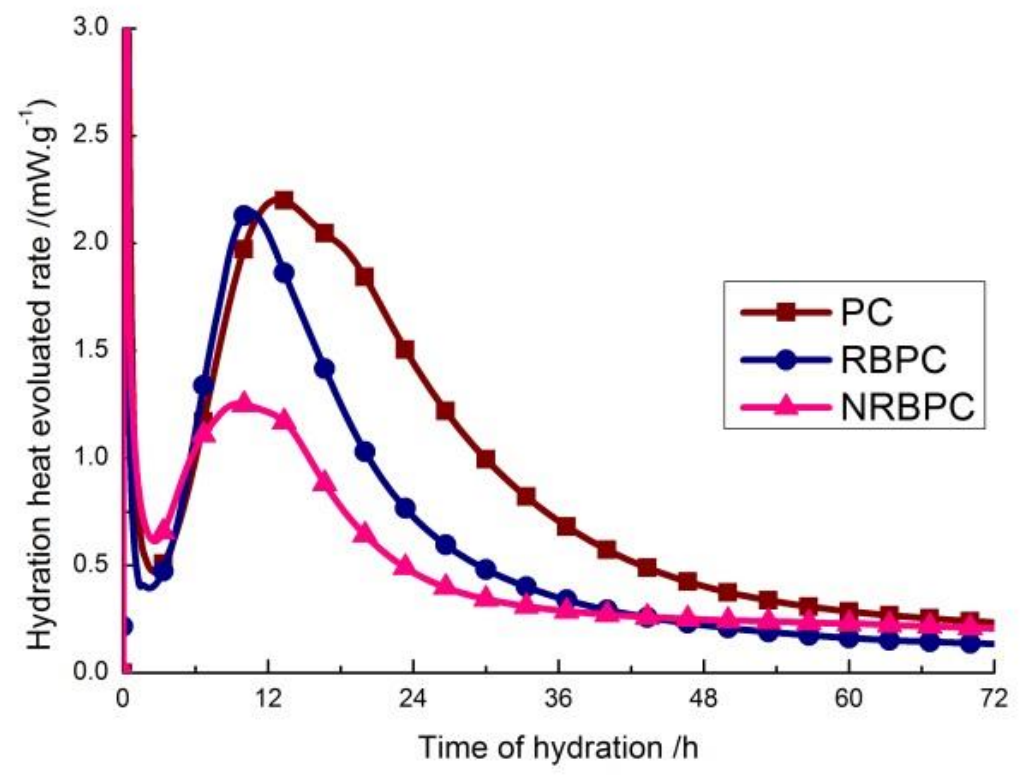

Figure 10. Hydration Heat Evolution Rate of Three Cements

The hydration exothermic peak of NRBPC is significantly lower than others within 3-day hydration. Moreover, the accumulated hydration heat of NRBPC at 3-day is nearly $60 \%$ of PC and lower than RBPC.

In order to compensate the lower early strength gain of RBPC and NRBPC, CSA mineral is introduced to form a new clinker system as $\mathrm{C}_{2} \mathrm{~S}-\mathrm{C}_{4} \mathrm{~A}_{3} \overline{\mathrm{S}}-\mathrm{C}_{4} \mathrm{AF}$, i.e., BCSA. One unique property of BCSA lies in its rapid setting and quick hardening. The difference between BCSA and PC can also be clearly found from strength development shown in figure 11. Further work is in progress to make this promising new type of cement competitive with PC. 


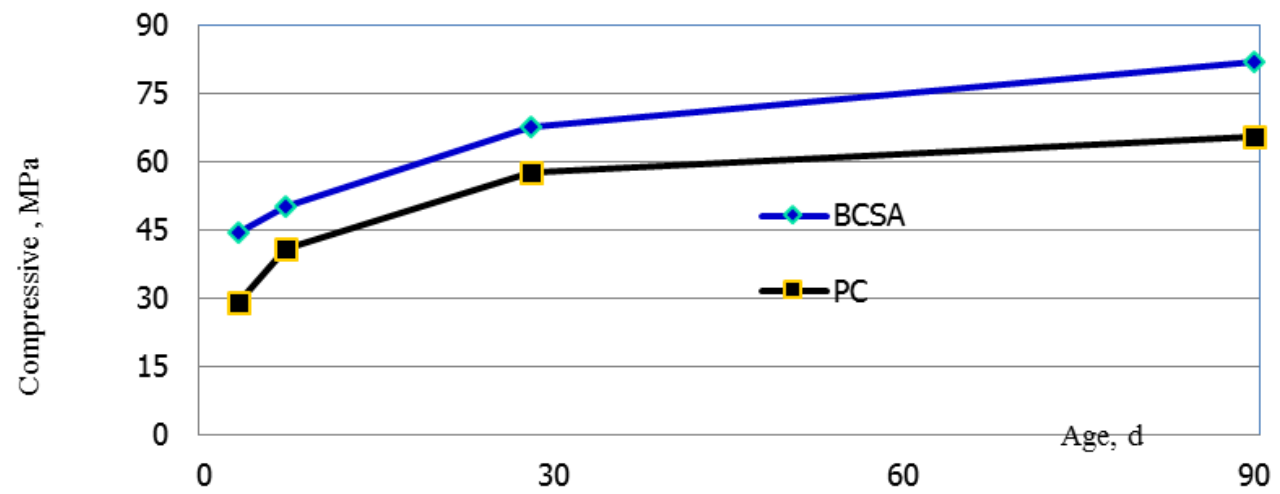

Figure11. Strength Development of BCSA and PC

\section{CONCLUSION}

- Co-processing of MSW with cement kilns has been demonstrated a technically feasible, environmentally sound and economically viable solution to address the cyclic economy and sustainability. With the operation of co-processing demonstration project in Liyang city with a population of 800 thousand, MSW is $100 \%$ recycled, creating a model of sustainable city in China.

- The key factors for Co-processing of MSW include the content of moisture and interference elements such as chloride in MSW.

- Properties of Belite based low carbon clinker cements feature in many aspects as compared with PC. Belite based low heat cements such as RBPC and NRBPC exhibit lower hydration heat and higher later age strength and durability, while belite based BCSA shows promising better results comparing with PC at all hydration ages.

- Intensive work should be done as an effort to make such low carbon clinker cements being used in an increasingly larger volume as advanced supplementary cements to normal PC for future solution towards cement and concrete sustainability.

\section{ACKNOWLEDGEMENT}

The Authors kindly acknowledge the support of Key Research Project at the $9^{\text {th }}, 10^{\text {th }}$ and $11^{\text {th }}$ Five-Year Program from Ministry of Science \& Technology of China and all the members involved in these projects.

\section{REFERENCES}

Chen L., Yang X., Xin M., (2010), The influence analysis on composition and its fluctuation of the Municipal Solid Waste to kiln system [J]. China Cement, 9:19 21 (in Chinese)

Chatterjee, A. K., (1996), "High belite cements - present status and future technological options: Part I." in: Cement and Concrete Research, 26(8), pp.1213-1225.

Gartner E., Quillin K. (2007), Low- $\mathrm{CO}_{2}$ Cements Based on Calcium Sulfoaluminates. In: International 
Conference on Sustainability in the Cement and Concrete Industry, Lillehammer, Norway, September $16-19$

Glasser, F. P., Zhang, L., (2001), "High-Performance Cement Matrices Based on Calcium Sulfoaluminate-Belite Compositions," Cement and Concrete Research, Vol. 31, No. 12, pp. 1881-1886

Mehta, P. K. (1980), “Investigations on Energy-Saving Cements,” World Cement Technology, pp. 166-177

Sui T., Guo S., Liu K., et al, (1998), Research on High Belite Cement, in: Part I\& II, 4th Beijing International Symposium on Cement and Concrete, October26-29

Sui, T., Liu, K. et al. (1999), Study on the Properties of High Belite Cement, in: Journal of Chinese Ceramic Society, No.4, 488-492 (in Chinese)

Sui, T. et al, (2003) Recent Progress in Special Cements in China, in: Proceeding of the 11th International Congress on the Chemistry of Cement, Vol. 4, Durban, South Africa, 11-16 May, pp.2028-2032

Sui, T., Fan, L., Wen Z., et al. (2004) Study on the Properties of High Strength Concrete using High Belite Cement. In: Journal of Advanced Concrete Technology, Japan Concrete Institute.,Vol.2, No.2, pp.201-206

Sui T., Li, J., Peng, X., et al, (2006), A Comparison of HBC and MHC Massive Concrete for Three Gorges Project in China, in: Proceedings of Measuring, Monitoring and Modeling Concrete Properties, Greece, pp.341-346

Taylor, H.F.W., (1997) Cement Chemistry, 2nd ed. London: Thomas Telford ,

Yang X., Cai ,Y., (2003), An effective way to volume reduction and resource of MSW[J]. China Cement, 3:28 30 (in Chinese) 